\title{
$\beta$-Carotene Prevents Bile Acid-Induced Cytotoxicity in the Rat Hepatocyte: Evidence for an Antioxidant and Anti-Apoptotic Role of $\beta$-Carotene In Vitro
}

\author{
ERIC GUMPRICHT, ROLF DAHL, MICHAEL W. DEVEREAUX, AND RONALD J. SOKOL \\ Pediatric Liver Center and Liver Transplantation Program, Section of Pediatric Gastroenterology, \\ Hepatology and Nutrition, Department of Pediatrics, University of Colorado School of Medicine and The \\ Children's Hospital, Denver, Colorado 80262, U.S.A.
}

\begin{abstract}
ABST
Hydrophobic bile acids are implicated in the pathogenesis of
cholestatic liver disorders through mechanisms involving oxida-
tive stress and mitochondrial dysfunction. Antioxidants amelio-
rate bile acid-induced cytotoxicity in rat hepatocyte suspensions.
The purpose of the current study was to evaluate the potential
protective role of $\beta$-carotene $(\beta C)$, a putative fat-soluble antiox-
idant that is reduced in patients with cholestasis, against bile
acid-induced hepatotoxicity. In freshly isolated rat hepatocyte
suspensions that were exposed to the toxic hydrophobic bile acid
glycochenodeoxycholic acid (100 or $500 \mu \mathrm{M}), \beta \mathrm{C}$ (100 $\mu \mathrm{M})$
decreased generation of reactive oxygen species by $>50 \%$,
similar to the inhibition afforded by $\alpha$-tocopherol. Commensu-
rate with this antioxidant effect, $100 \mu \mathrm{M} \beta \mathrm{C}$ also protected
hepatocytes against both glycochenodeoxycholic acid-induced
cellular necrosis and apoptosis, which was associated with re-
duction in caspase 3 activation, inhibition of mitochondrial cy-
tochrome c release in rat hepatocytes, and prevention of the
mitochondrial permeability transition in both liver mitochondria
and rat hepatocytes. A lower concentration of $\beta \mathrm{C}$ (50 $\mu \mathrm{M})$
produced similar antioxidant and anti-apoptotic protection but
\end{abstract}
The preventive roles of dietary antioxidants, such as vitamin $\mathrm{E}$ (including tocopherols and tocotrienols) and ascorbic acid, have been evaluated extensively as potential protective agents toward several diseases or conditions in humans, including cancer, heart disease, and cataractogenesis (see Refs. 1 and 2 for overviews). The mechanism of protection afforded by these agents is generally consistent with their antioxidant activities, although inhibition of cellular mediators, including protein

Received July 17, 2003; accepted December 11, 2003.

Correspondence: Ronald J. Sokol, MD, Department of Pediatrics, Box B290, The Children's Hospital, 1056 E. 19th Avenue, Denver, CO 80218, U.S.A.; e-mail: sokol.ronald@tchden.org

Supported in part by grants from the National Institutes of Health (RO1 DK-38446) and the Abby Bennett Liver Research Fund.

DOI: 10.1203/01.PDR.0000117845.23762.6B with less inhibition against cell necrosis, suggesting that the higher concentration of $\beta \mathrm{C}$ may have conferred additional cytoprotection not directly related to its antioxidant function. These results demonstrate that the antioxidant effects of $\beta \mathrm{C}$ may provide hepatoprotection against cholestatic liver injury by preventing bile acid-induced oxidative stress and mitochondrial perturbations. (Pediatr Res 55: 814-821, 2004)
$\alpha$-TH, $\alpha$-tocopherol
Abbreviations
$\boldsymbol{\beta C}, \beta$-carotene
CLD, cholestatic liver disorders
DCF-DA, dichlorofluorescin diacetate
DCFein, 2'7'-dichlorofluorescein
GCDC, glycochenodeoxycholic acid
KRH, Krebs Ringers HEPES
MPT, mitochondrial permeability transition
PI, propidium iodide
ROS, reactive oxygen species
$\Delta \psi$, mitochondrial electrochemical gradient

kinases and eicosanoids, have also been implicated $(3,4)$. In addition to these antioxidant vitamins, $\beta$-carotene $(\beta C)$ may function as a physiologically relevant antioxidant along with its well-defined role as a precursor to vitamin A (for review, see Ref. 5). However, despite the seminal report by Burton and Ingold (6), who found that $\beta C$ functioned as an efficient antioxidant in chemical systems, recent large-scale human studies with the carotenoid have been disappointing. For example, $\beta C$ failed to protect human subjects against lung cancer and coronary artery disease $(7,8)$. Consequently, the Panel on Dietary Antioxidants and Related Compounds of the Food and Nutrition Board of the Institute of Medicine determined that $\beta C$ does not meet the definition of a dietary antioxidant and that $\beta C$ supplementation should not be recommended (9). In contrast to the studies that evaluated $\beta C$ 's role in the preven- 
tion of cancer and atherosclerosis, few studies have addressed the potential protective effects of $\beta C$ in hepatobiliary diseases. Recent reports show that 1) $\beta C$ is malabsorbed in various hepatobiliary diseases $(10-12) ; 2)$ serum $\beta C$ levels are very low in adults with the cholestatic liver disorders (CLD), primary biliary cirrhosis, and primary sclerosing cholangitis (12) and in children with cholestasis (13); and 3) antioxidant therapy improved symptoms in patients with cholestasis in a recent pilot study (14). Thus, a lack of adequate $\beta C$ may play a role in potentiating liver injury in CLD.

Recent studies from our laboratory demonstrate in both in vivo and in vitro models that oxidative stress is a key mediator for the hepatic injury observed in CLD. These diseases, characterized by an impairment of bile flow or secretion that results in increased concentrations of bile constituents within the liver and subsequent hepatotoxicity, include biliary atresia, neonatal hepatitis, progressive familial intrahepatic cholestasis, a variety of metabolic liver disorders, cystic fibrosis, and primary sclerosing cholangitis in childhood. Because treatment for many of these disorders is inadequate, liver transplantation is frequently required in affected children and adults (15). One primary factor implicated in cholestasis is the accumulation of hydrophobic bile acids within the liver (16), which have been demonstrated to be toxic to freshly isolated and cultured hepatocytes, liver mitochondria, and whole animals (17-20). Hepatocytes that are exposed to lower concentrations of hydrophobic bile acids ( $\leq 100 \mu \mathrm{M})$ typically undergo apoptotic cell death $(20,21)$, whereas at higher concentrations, these compounds promote cell necrosis through oxidative stress, ATP depletion, hepatocyte swelling, and disruption of the plasma membrane $(17,20)$. Both modes of bile acid-induced cell death are believed to be important in the pathogenesis of CLD through generation of oxidative stress $(17,22)$.

Mechanistic studies of bile acid-induced apoptosis and/or necrosis have also focused attention on induction of the mitochondrial permeability transition (MPT) as a critical event preceding cell death $(19,23-25)$. The MPT is characterized by large-amplitude swelling and loss of the electrochemical potential across the inner mitochondrial membrane caused by opening of a megachannel (MPT pore) spanning both the inner and the outer mitochondrial membranes $(26,27)$. Upon induction of the MPT, several intermembranous space proteins are released into cytosol, including the pro-apoptotic signal cytochrome $\mathrm{c}$ and several inhibitors of apoptosis (28). Of particular interest are findings correlating increased generation of reactive oxygen species (ROS) with stimulation of the MPT by bile acids $(19,22,25)$, most likely via the oxidative modification of MPT pore proteins (29). Commensurate with their ability to inhibit the MPT and cytochrome c release from mitochondria, antioxidants such as $\alpha$-tocopherol $(\alpha-\mathrm{TH})$, ebselen, and idebenone also reduce bile acid-induced cellular necrosis and apoptosis in rat hepatocytes $(17,25)$.

Because $\beta C$ has been proposed as an antioxidant and levels of $\beta C$ are low in cholestatic liver injury, the current study was performed to determine the potential antioxidant and cytoprotective effects of $\beta C$ toward glycochenodeoxycholic acid (GCDC)-induced hepatocyte toxicity by addressing the following questions that are relevant to the pathogenesis of CLD: 1)
Can $\beta C$ function as an antioxidant in rat hepatocytes that are exposed to a bile acid-induced oxidative stress? 2) Can $\beta C$ prevent bile acid-induced hepatocyte cytotoxicity? 3) What are the mechanisms responsible for the cytoprotective effects afforded by $\beta C$ against bile acid-induced hepatotoxicity?

\section{METHODS}

All chemicals were obtained in reagent-grade quality from suppliers. BSA-fraction V (BSA) and alcohol-soluble digitonin were obtained from Calbiochem (La Jolla, CA, U.S.A.). GCDC $\left(\mathrm{Na}^{+}\right.$salt) and $\beta \mathrm{C}$ (type 1) were obtained from Sigma Chemical Co. (St. Louis, MO, U.S.A.). 2,7-dichlorofluorescin diacetate (DCF-DA) was purchased from Eastman Kodak Co. (Rochester, NY, U.S.A.), and the fluorescent probe JC-1 was purchased from Molecular Probes (Eugene, OR, U.S.A.). R,R,R- $(\alpha-\mathrm{TH})$ was obtained from Fisher Scientific (Pittsburgh, PA, U.S.A.). All other reagents unless stated were reagent grade or better.

Isolation of rat hepatocytes and liver mitochondria. Humane care was given to all experimental animals, and this study was approved by the Institutional Animal Care and Use Committee of the University of Colorado Health Sciences Center. Hepatocytes were isolated by a recirculating collagenase technique from 175 - to 225 -g male Sprague Dawley rats (Sasco, Inc., Omaha, NE, U.S.A.) maintained on a 12-h lightdark cycle and fed standard laboratory rat diet, as previously described (17). Initial hepatocyte viability measured by trypan blue exclusion was always $>94 \%$. Freshly isolated hepatocytes were resuspended in a Krebs Ringers HEPES (KRH) buffer containing $0.2 \% \mathrm{BSA}(\mathrm{KRH} / \mathrm{BSA})$ to a concentration of $\sim 1 \times$ $10^{6} / \mathrm{mL}$ and preincubated for $30 \mathrm{~min}$ at $37^{\circ} \mathrm{C}$ with $\beta \mathrm{C}(50$ or $100 \mu \mathrm{M}$, dissolved in DMSO), $100 \mu \mathrm{M} \alpha$-TH, or both $100 \mu \mathrm{M}$ $\beta \mathrm{C}$ and $\alpha$-TH to determine whether the antioxidant effects were additive or synergistic. After the preincubation period, 100 or $500 \mu \mathrm{M}$ GCDC was added and hourly aliquots of cell suspension were removed to determine their effects on ROS generation, cell necrosis, and apoptosis. For immunoblot analysis, aliquots were withdrawn after $3 \mathrm{~h}$ of incubation.

Measurement of ROS generation in rat hepatocytes. For determining whether $\beta \mathrm{C}$ could function as an antioxidant in this model, generation of ROS was measured by spectrofluorescence using the hydroperoxide detecting probe DCF-DA as previously described in detail (17). Briefly, hepatocytes were preloaded with DCF-DA for $30 \mathrm{~min}$ at $37^{\circ} \mathrm{C}$ before the addition of antioxidants. After an additional 30-min preincubation with antioxidants, hepatocytes were exposed to GCDC (100 or $500 \mu \mathrm{M}$ ) for $4 \mathrm{~h}$ and hourly aliquots were removed for analysis of ROS by measuring 2'7'-dichlorofluorescein (DCFein) fluorescence at 490-nm excitation and 520-nm emission. Results were expressed as picomoles per $10^{6}$ cells based on a standard curve using DCFein.

Determination of hepatocyte apoptosis and necrosis. Hepatocyte apoptosis was quantified by determining the percentage of hepatocytes with nuclear morphologic changes of apoptosis detected by fluorescence microscopy of 4'6-diamidino2-phenylindole-stained fixed hepatocytes, as previously described (21). Necrosis was determined by the release of 
lactate dehydrogenase activity from cells, as previously described (21), and expressed as the percentage of total cellular activity released into the media.

Immunoblot analysis of cytochrome c release and caspase 3 activation. To determine the extent of mitochondrial cytochrome $\mathrm{c}$ release in isolated rat hepatocytes that were exposed to $\mathrm{GCDC}$ and $\beta \mathrm{C}$, we used the protocol of selective digitonin permeabilization as originally described by Leist et al. (30) and as modified by Qiao et al. (31). Briefly, after $3 \mathrm{~h}$ of incubation with $100 \mu \mathrm{M}$ GCDC with or without antioxidants, $4-6 \times 10^{6}$ cells were pelleted by centrifugation, washed once with KRH buffer (no BSA), and recentrifuged to obtain hepatocyte pellets. Hepatocytes were resuspended in a cell permeability buffer containing $75 \mathrm{mM} \mathrm{NaCl}, 8 \mathrm{mM} \mathrm{Na} \mathrm{HPO}_{4}, 1 \mathrm{mM}$ $\mathrm{NaH}_{2} \mathrm{PO}_{4}, 1 \mathrm{mM}$ EDTA, and $250 \mathrm{mM}$ sucrose $(\mathrm{pH}$ 7.4) containing $350 \mu \mathrm{g} / \mathrm{mL}$ digitonin for $30 \mathrm{~s}$ and centrifuged at $13,000 \times g$ for $1 \mathrm{~min}$. The cytosolic supernatant fraction was collected, and protein concentration was determined by Lowry et al. (32). Approximately 15-25 $\mu \mathrm{g}$ of protein was loaded onto a $12 \%$ SDS-PAGE and transferred to nitrocellulose membrane and probed with $1-2 \mu \mathrm{g} / \mathrm{mL}$ purified mouse anticytochrome c MAb (BD Biosciences, San Diego, CA, U.S.A.). Cytochrome $\mathrm{c}$ was detected colorimetrically with stabilized 3,3',5,5'-tetramethylbenzidine (Promega, Madison, WI, U.S.A.) and quantified by densitometry using UN-SCAN-IT gel software (Silk Scientific, Orem, UT, U.S.A.).

For caspase 3 immunoblotting, a cytosolic fraction was obtained as follows: $2 \times 10^{6}$ cells were pelleted by centrifugation, washed once with KRH buffer (no BSA), and recentrifuged to obtain hepatocyte pellets. Cells were lysed by the addition of 200-300 $\mu \mathrm{L}$ of 3-[3-cholamidopropyl)dimethyl, ammonio]-1-propanesulfonate Cell Extract Buffer (Cell Signaling Technology, Beverly, MA, U.S.A,) containing $5 \mathrm{mM}$ DTT and $1 \mathrm{mM}$ phenylmethylsulfonyl fluoride. The cell suspension was subjected to three freeze-thaw cycles before centrifugation at $13,000 \times g$ for $5 \mathrm{~min}$. The supernatants were collected, and protein concentration was determined by the Bradford assay (33). Electrophoresis and analysis were carried out as described for cytochrome c except that 50-100 $\mu \mathrm{g}$ of protein was loaded onto $12 \%$ SDS-PAGE, and the blots were incubated with 1:50 dilution of mouse monoclonal anticaspase 3 (Santa Cruz Biotechnology, Santa Cruz, CA, U.S.A.). Equal loading was confirmed in selected experiments by also probing blots against a 1:5000 dilution of anti-actin $\mathrm{MAb}$ followed by a 1:2000 dilution of goat anti-mouse IgMspecific horseradish peroxidase (Oncogene Research Products, Boston, MA, U.S.A.).

Flow cytometry. Flow cytometric analysis was performed to determine the effect of $\beta C$ on GCDC-induced MPT in freshly isolated hepatocytes, as previously described in detail (34). Briefly, freshly isolated hepatocytes were pretreated with 50 $100 \mu \mathrm{M} \beta \mathrm{C}$ for $30 \mathrm{~min}$ before exposure to $100 \mu \mathrm{M}$ GCDC for $4 \mathrm{~h}$. Hourly aliquots of cells were removed, loaded with 7.6 $\mu \mathrm{M} \mathrm{JC}-1$ or $3 \mu \mathrm{M}$ propidium iodide (PI) for $15 \mathrm{~min}$ at $22^{\circ} \mathrm{C}$ in the dark, and washed with $\mathrm{KRH}$ buffer at $4^{\circ} \mathrm{C}$ before flow cytometry on a Becton Dickinson FACS Calibur (Becton Dickinson Immunocytometry Systems, San Jose, CA, U.S.A.) using CELLQuest software. In actively respiring mitochondria,
JC-1 aggregates form and the intensity of their fluorescence at $590 \mathrm{~nm}$ is proportional to the mitochondria mitochondrial electrochemical gradient $(\Delta \psi)$ and indicative of a closed MPT pore ( $\beta \mathrm{C}$ alone had no effect on JC-1 fluorescence). Approximately 10,000 cells were analyzed for each time point and treatment. The fluorescence of JC-1 aggregates was determined only in live cells (as determined by PI staining) by gating on hepatocytes that showed no uptake of PI.

Measurement of the MPT. Rat liver mitochondria were isolated by differential centrifugation of liver homogenate through a Percoll gradient, and the MPT assay was performed as previously described in detail (22). Briefly, hepatic mitochondria $(1.5-3.0 \mathrm{~mL})$ in respiration buffer $[125 \mathrm{mM}$ sucrose, $100 \mathrm{mM} \mathrm{NaCl}, 10 \mathrm{mM}$ MOPS (pH 7.4) treated with $1 \%$ Chelex-100] were incubated at $25^{\circ} \mathrm{C}$ for $5 \mathrm{~min}$ alone or in the presence of $10-250 \mu \mathrm{M} \beta \mathrm{C}$. After the preincubation period, $100 \mu \mathrm{M} \mathrm{CaCl}_{2}, 5 \mathrm{mM}$ sodium succinate, and $5 \mu \mathrm{M}$ rotenone (in dimethylformamide) were added to mitochondria, and the absorbance at $540 \mathrm{~nm}$ was monitored for $5 \mathrm{~min}$. The MPT was then induced by the addition of $100 \mu \mathrm{M}$ GCDC, and absorbance was monitored continuously for an additional $5 \mathrm{~min}$.

Statistical analysis. Mean and SEM were calculated for each time point. Comparisons among groups were performed by ANOVA and the Scheffe test or $t$ test when appropriate. $P<$ 0.05 was considered statistically significant.

\section{RESULTS}

$\beta$-carotene reduces $G C D C$-stimulated ROS generation. Because the antioxidative function of $\beta \mathrm{C}$ in biologic systems is controversial (35), we first undertook an evaluation of the effect of $\beta C$ on ROS generation under conditions of excess hydrophobic bile acids that may exist in the cholestatic liver. Freshly isolated rat hepatocyte suspensions that were exposed to either 100 or 500 $\mu \mathrm{M}$ GCDC generated increased ROS (hydroperoxides) in a timedependent manner when compared with untreated cells (Fig. 1a and $b$ ). Pretreatment with $\beta \mathrm{C}$ led to a $>50 \%$ reduction in ROS generation in GCDC-exposed hepatocytes at $4 \mathrm{~h}$ and was not dose dependent. The effects of $\beta C$ were compared with that observed with $\alpha$-TH, an antioxidant previously demonstrated to inhibit ROS generation in rat hepatocytes and liver mitochondria that were exposed to $\operatorname{GCDC}(17,22)$. Figure $1 c$ indicates that the antioxidative potencies of $\beta \mathrm{C}$ and $\alpha$-TH were identical in preventing ROS generation in rat hepatocytes that were exposed to $100 \mu \mathrm{M}$ GCDC and that no additive or synergistic effects were observed when the antioxidants were combined.

$\beta C$ protects rat hepatocytes against GCDC-induced cell necrosis and apoptosis. We next sought to determine whether the observed antioxidative effect of $\beta C$ was associated with cytoprotection against GCDC-induced necrosis and apoptosis. To assess the effects of varying concentrations of $\beta C$ on GCDC-induced cell necrosis, rat hepatocyte suspensions were exposed to either 100 or $500 \mu \mathrm{M} \mathrm{GCDC}$, and cell necrosis was quantified by release of lactate dehydrogenase from cells. By $4 \mathrm{~h}$ of incubation (Fig. $2 a$ and $b$ ), GCDC caused significant cell necrosis at both GCDC concentrations when compared with untreated cells $(14 \pm 1 \%$ for control versus $35 \pm 2 \%$ for 100 $\mu \mathrm{M}$ GCDC versus $47 \pm 4 \%$ for $500 \mu \mathrm{M}$ GCDC). Preincuba- 


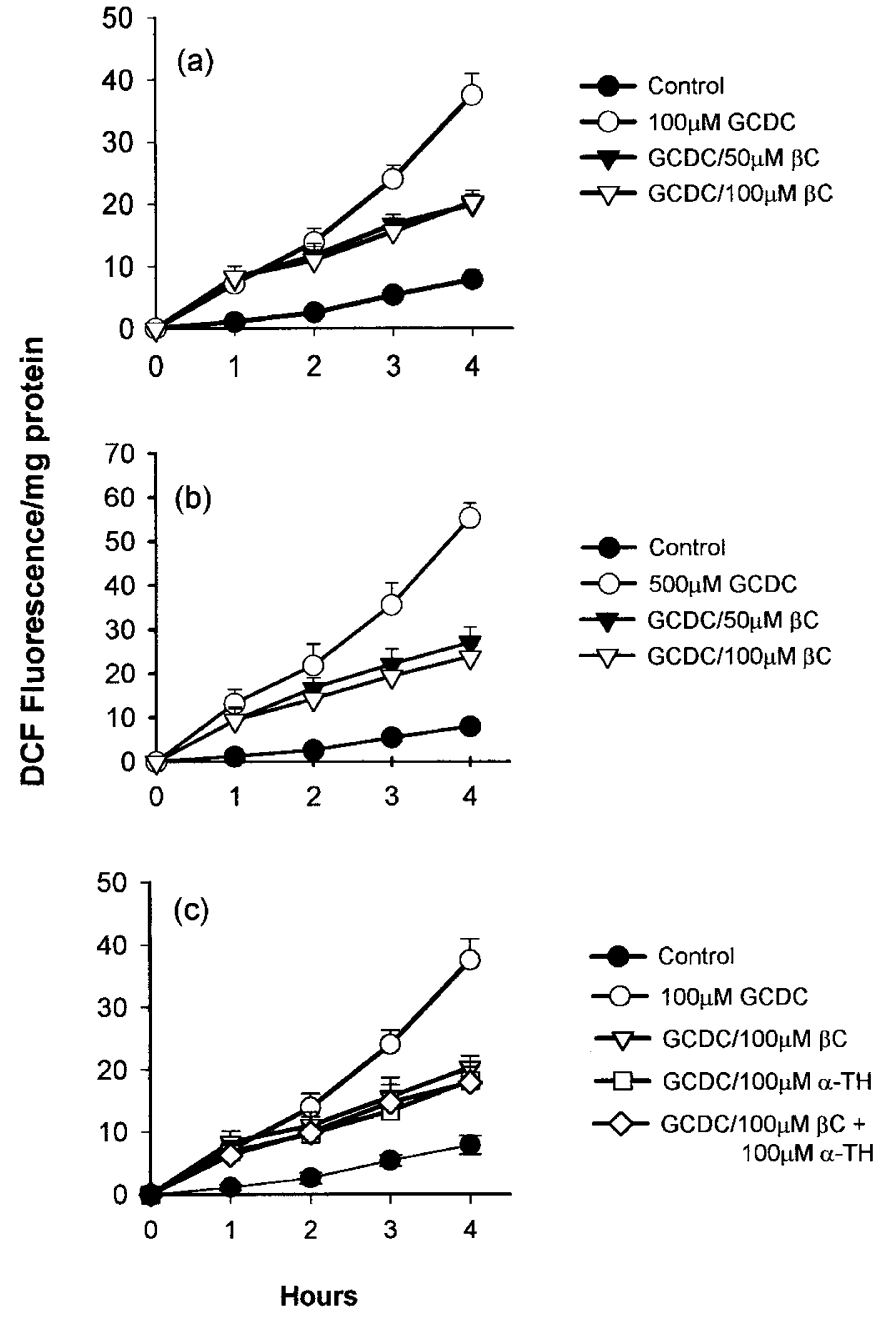

Figure 1. $\beta C$ prevents generation of ROS in isolated rat hepatocytes that were exposed to GCDC. Hepatocytes $\left(10^{6} / \mathrm{mL}\right)$ were loaded with $10 \mu \mathrm{M}$ DCF-DA for $30 \mathrm{~min}$ at $37^{\circ} \mathrm{C}$ and, where indicated, preincubated for an additional $30 \mathrm{~min}$ with $\beta \mathrm{C}(50-100 \mu \mathrm{M})$ or vehicle before the addition of either $100 \mu \mathrm{M}(a)$ or $500 \mu \mathrm{M}(b)$ GCDC. (c) The antioxidative effect of $100 \mu \mathrm{M} \beta C$ was compared with that of $100 \mu \mathrm{M} \alpha-\mathrm{TH}$ alone or in combination. Hourly aliquots were removed, and ROS generation was determined by fluorescence of DCFein, as described in "Methods." Results are expressed as mean \pm SEM of at least four separate experiments.

tion of cells with $100 \mu \mathrm{M} \beta \mathrm{C}$ protected hepatocytes against cellular necrosis, whereas the lower concentration of $\beta \mathrm{C}$ (50 $\mu \mathrm{M})$ protected hepatocytes against $100 \mu \mathrm{M}$ GCDC but not $500 \mu \mathrm{M}$ of the bile acid. When cells were exposed to 100 $\mu \mathrm{M}$ GCDC, a significant increase in protection was afforded by the combination of $100 \mu \mathrm{M} \beta \mathrm{C}$ and $100 \mu \mathrm{M} \alpha$-TH compared with $100 \mu \mathrm{M} \beta \mathrm{C}$ or $\alpha$-TH alone (Fig. $2 c$ ).

Isolated rat hepatocytes that are exposed to $100 \mu \mathrm{M}$ GCDC undergo significant apoptosis by $2 \mathrm{~h}$, which continues to increase by $4 \mathrm{~h}$ of incubation (Fig. 3; 43\% of GCDC-treated cells versus $1 \%$ untreated cells at $4 \mathrm{~h}$ ). Pretreating hepatocytes with $50 \mu \mathrm{M} \beta \mathrm{C}$ reduced bile acid-induced apoptosis by approximately $50 \%$ at $2 \mathrm{~h}$ and $35 \%$ at $4 \mathrm{~h} ; 100-\mu \mathrm{M} \beta \mathrm{C}$ concentration was associated with somewhat better protection against apoptosis at $4 \mathrm{~h}$. Pretreating cells with $100 \mu \mathrm{M} \alpha$-TH led to a similar reduction of GCDC-induced apoptosis as that produced
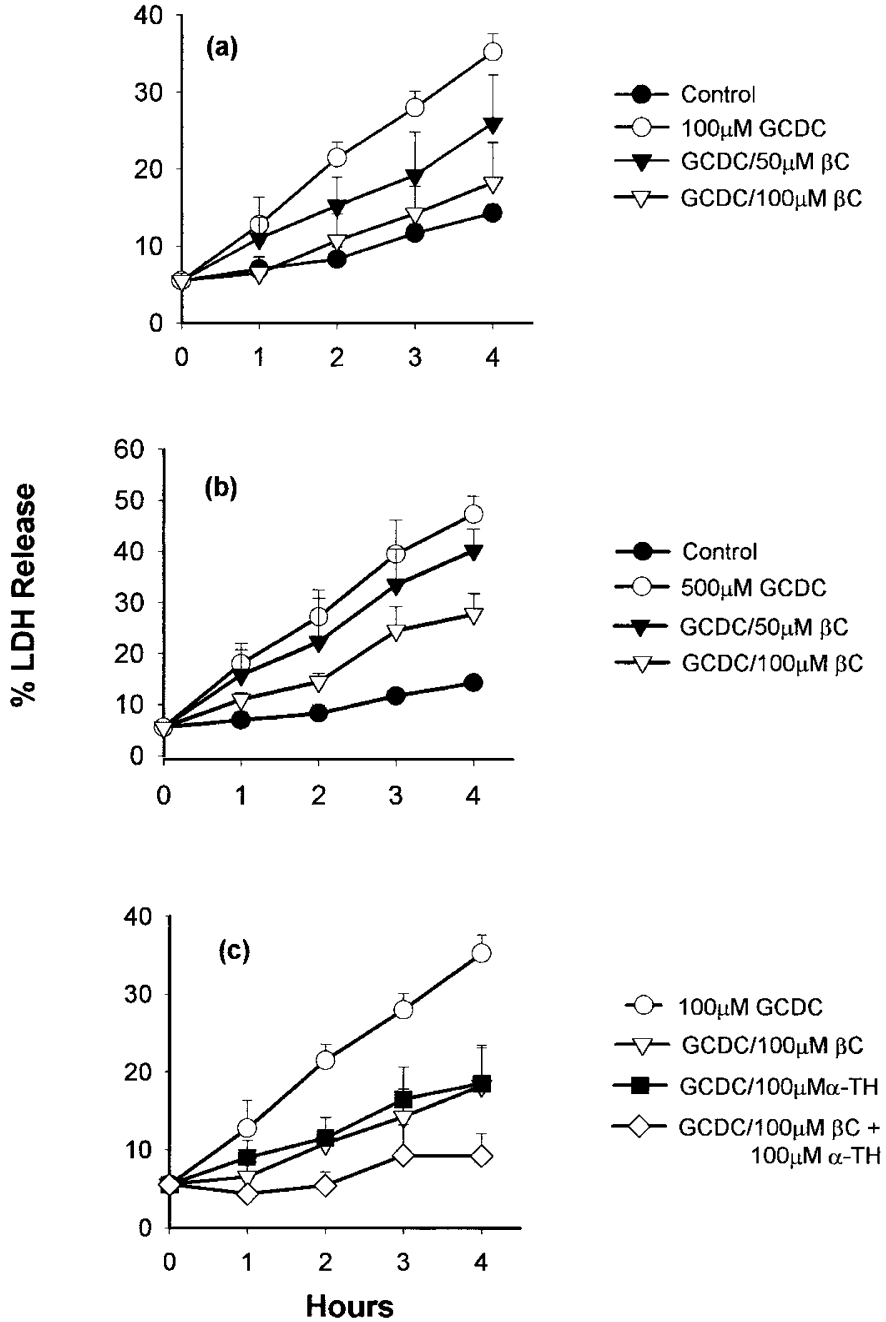

Figure 2. $\beta C$ inhibits GCDC-induced cellular necrosis in isolated rat hepatocytes. Hepatocytes were preincubated for $30 \mathrm{~min}$ at $37^{\circ} \mathrm{C}$ with $\beta \mathrm{C}(50-100$ $\mu \mathrm{M})$ or vehicle before the addition of either $100 \mu \mathrm{M}(a)$ or $500 \mu \mathrm{M}(b)$ GCDC to promote cell necrosis. (c) The antioxidative effect of $100 \mu \mathrm{M} \beta \mathrm{C}$ was compared with that of $100 \mu \mathrm{M} \alpha$-TH alone or in combination. Hourly aliquots were removed for determination of cell necrosis (\% lactate dehydrogenase release), as described in "Methods." Results are expressed as mean \pm SEM of at least four separate experiments.

by $100 \mu \mathrm{M} \beta \mathrm{C} ; 100 \mu \mathrm{M} \beta \mathrm{C}$ combined with $\alpha$-TH had a mild additive protective effect (data not shown).

Inhibition by $\beta C$ of $G C D C$-induced MPT in liver mitochondria. Induction of the MPT by a variety of toxic agents is believed to be a critical step in mediating cell death by necrotic and apoptotic pathways. GCDC $(100 \mu \mathrm{M})$ led to a rapid decrease in absorbance of liver mitochondria at $540 \mathrm{~nm}$, representative of mitochondrial swelling and induction of the MPT. $\beta C$ exerted a dose-dependent inhibition of the MPT in this model (Fig. 4a). The MPT was verified by the complete inhibition of the GCDC-induced mitochondrial swelling by preincubation with cyclosporin A. A comparison of the dose-dependent effects of $\beta \mathrm{C}$ and $\alpha$-TH on GCDC-induced MPT (Fig. 4b) shows that the profile of MPT inhibition afforded by each of the antioxidants is nearly identical.

Effect of $\beta C$ on $G C D C$-induced cytochrome c release and caspase 3 levels. The suppression of bile acid-induced he- 


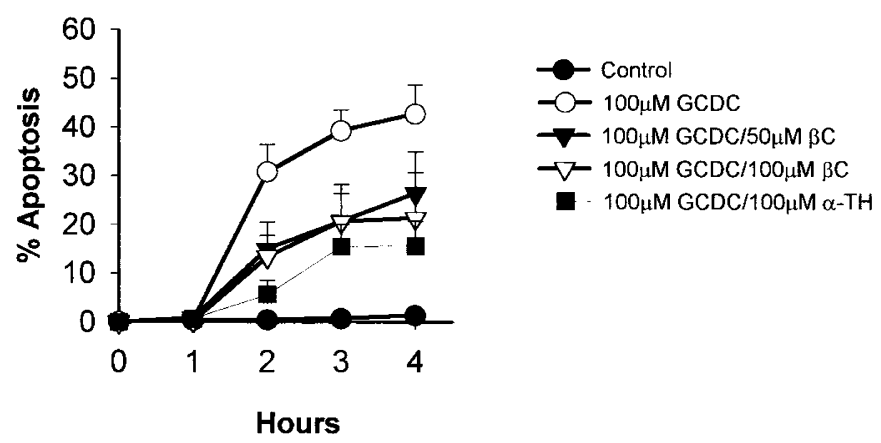

Figure 3. $\beta C$ inhibits GCDC-induced apoptosis in isolated rat hepatocytes. Hepatocytes were preincubated for $30 \mathrm{~min}$ at $37^{\circ} \mathrm{C}$ with $\beta \mathrm{C}(50-100 \mu \mathrm{M})$, $\alpha-\mathrm{TH}$, or vehicle before the addition of $100 \mu \mathrm{M}$ GCDC to induce cell apoptosis. Hourly aliquots were removed for determination of apoptosis as assessed by the percentage of cells with nuclear morphologic changes observed under fluorescence microscopy, as described in "Methods." Results are expressed as mean \pm SEM of at least four separate experiments.

patocyte apoptosis by $\beta \mathrm{C}$ suggests that the carotenoid may alter critical steps in the induction of hepatocyte apoptosis. Therefore, we determined the effect of $\beta C$ on two important events in the execution of hepatocytes apoptosis, release of cytochrome $\mathrm{c}$ from mitochondria and activation of caspase 3 (Fig. 5). Examination of postmitochondrial supernatant from hepatocytes that were treated with $100 \mu \mathrm{M}$ GCDC indicated that exposure to GCDC for $3 \mathrm{~h}$ stimulated release of cytochrome $\mathrm{c}$ from mitochondria when compared with untreated hepatocytes (Fig. $5 a$ ). Pretreating cells with $100 \mu \mathrm{M} \beta \mathrm{C}, 100$ $\mu \mathrm{M} \alpha-\mathrm{TH}$, or the combination abrogated release of cytochrome c from mitochondria. To determine the effect of antioxidants on GCDC-stimulated caspase 3 activation, we analyzed the amount of procaspase 3 levels in cytosol of hepatocytes by immunoblotting (Fig. 5b). Results from these experiments demonstrated that procaspase 3 in cells exposed to $100 \mu \mathrm{M}$ GCDC for $3 \mathrm{~h}$ was reduced, indicative of caspase 3 activation (Fig. 5b). Pretreating hepatocytes with $\beta \mathrm{C}, \alpha$-TH, or the combination prevented the reduction of procaspase levels, concomitant with protection against apoptosis (Fig. 3). Similar loading of lanes with cytosol was indicated by the immunoblots for $\beta$-actin (Fig. $5 c$ ).

$\beta C$ prevents $G C D C$-induced mitochondrial depolarization in rat hepatocytes. Induction of the MPT is associated with increased oxidative stress in hepatocytes that were treated with hydrophobic bile acids. Inasmuch as $\beta C$ reduced ROS generation and inhibited the MPT in isolated mitochondria, we next determined whether $\beta \mathrm{C}$ affected the MPT in live hepatocytes. To measure MPT in intact cells, we assessed mitochondrial $\Delta \psi$ in isolated hepatocytes by flow cytometric analysis using the probe JC-1 (Fig. 6). Exposure of hepatocytes to $100 \mu \mathrm{M}$ GCDC caused a significant decrease in fluorescence of JC-1 aggregates in hepatocytes at $2 \mathrm{~h}$, indicative of reduction of mitochondrial $\Delta \psi$ and opening of the MPT pore. Pretreating cells with $50-100 \mu \mathrm{M} \beta \mathrm{C}$ significantly prevented the reduction in JC-1 aggregate fluorescence at 3 and $4 \mathrm{~h}$. These results demonstrate that $\beta \mathrm{C}$ blocked the MPT concurrent with inhibition of ROS generation and reduced activation of caspase 3 and inhibition of apoptosis.
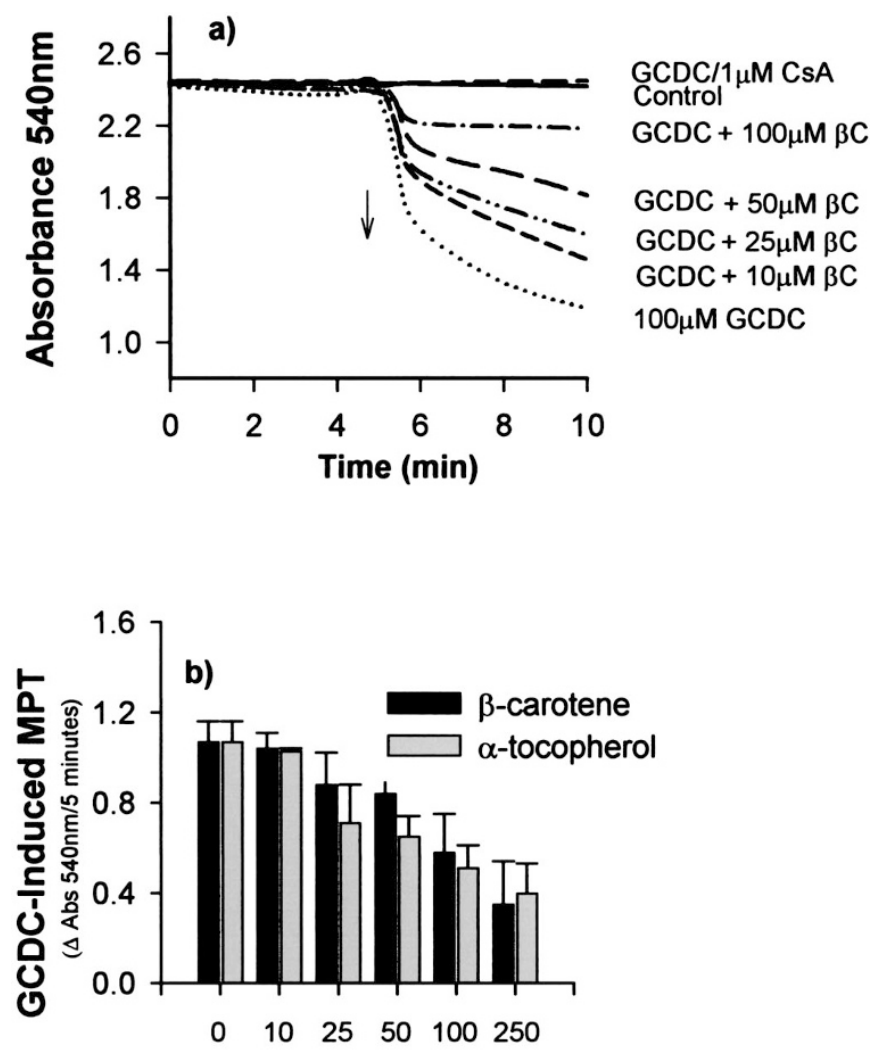

\section{Antioxidant Concentration $(\mu \mathrm{M})$}

Figure 4. Dose-dependent inhibition by $\beta C$ of GCDC-induced MPT in liver mitochondria. Suspensions of liver mitochondria were preincubated with $0-250 \mu \mathrm{M} \beta \mathrm{C}$ or $\alpha$-TH, or $1 \mu \mathrm{M}$ cyclosporin A (CsA) for $5 \mathrm{~min}$ before the addition of $100 \mu \mathrm{M}$ GCDC to induce the MPT. Mitochondrial swelling was measured spectrophotometrically as a reduction in absorbance at $540 \mathrm{~nm}$ over 5 min. (a) A typical tracing demonstrates the dose-dependent inhibition of MPT induced by $100 \mu \mathrm{M}$ GCDC in liver mitochondria and the complete blockage of MPT by CsA. (b) The dose-dependent protection against GCDCinduced MPT by $\beta \mathrm{C}$ and $\alpha$-TH is shown. MPT is expressed as the change in absorbance during the $5 \mathrm{~min}$ of exposure of mitochondria to $100 \mu \mathrm{M}$ GCDC. Results are expressed as mean \pm SEM of at least four separate experiments.

\section{DISCUSSION}

Results from the current study using an in vitro model of cholestatic liver injury demonstrate that $\beta \mathrm{C}$, a carotenoid of nutritional and physiologic significance, protects rat hepatocyte suspensions from hydrophobic bile acid-induced cell apoptosis by a mechanism consistent with its putative antioxidant activity. Concentrations of $\beta C$ in human liver vary widely, with its concentration in nonsupplemented individuals ranging from 6 to $25 \mathrm{nmol} / \mathrm{g}$ liver $(35,36)$. Assuming $140,000 \times 10^{6}$ hepatocytes $/ \mathrm{g}$ wet weight of liver, with $5 \mu \mathrm{L}$ of water per $10^{6}$ hepatocytes (37), the range of liver concentrations of $\beta C$ are converted to 9-36 $\mu \mathrm{M}$. However, in hepatobiliary disorders, concentrations of liver and serum $\beta \mathrm{C}$ are substantially decreased $(10,12,13,36)$. Therefore, the concentrations of $\beta C$ chosen in this study are close to the range of normal values, particularly when considering the accelerated time course needed to achieve intracellular $\beta \mathrm{C}$ concentrations in isolated hepatocyte incubations. 
a)

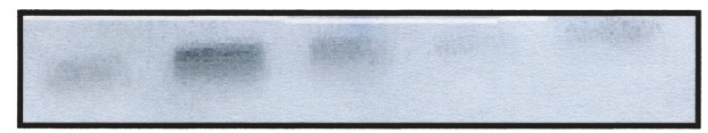

b)

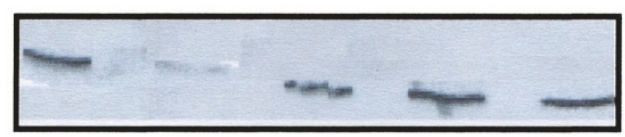

c)

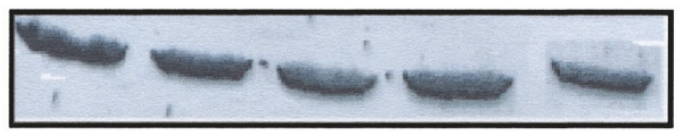

C GCDC GCDC GCDC GCDC $\beta C \quad \alpha-\mathrm{TH} \quad \beta C+\alpha-\mathrm{TH}$

Figure 5. $\quad \beta \mathrm{C}$ and $\alpha$-TH prevent GCDC-induced cytochrome c release and caspase 3 activation in rat hepatocytes. The effects of $\beta \mathrm{C}(100 \mu \mathrm{M}), \alpha-\mathrm{TH}(100$ $\mu \mathrm{M})$, both antioxidants, or no treatment (control-C) on GCDC-induced cytochrome c release from mitochondria into cytosol of hepatocytes $(a)$ and caspase 3 activation $(b)$ were determined after $3 \mathrm{~h}$ of incubation, as described in "Methods." Samples of cytosol from hepatocytes were immunoblotted against mouse anti-cytochrome c MAb in $a$ or mouse anti-caspase 3 MAb in $b$. In selected experiments, blots that were probed with anti-caspase 3 antibodies were stripped and reprobed with anti-actin antibodies $(c)$ to demonstrate similar loading. Results shown are representative of at least two separate experiments.

The antioxidative effect and cytoprotection afforded by $\beta \mathrm{C}$ in these experiments were nearly identical to that of $\alpha-\mathrm{TH}$, an antioxidant previously reported to protect rat hepatocytes from bile acid-induced cell death $(17,18)$. The anti-apoptotic effect of $\beta \mathrm{C}$ was further characterized by demonstrating inhibition of both caspase 3 activation and loss of mitochondrial $\Delta \psi$ in cells that were exposed to the toxic bile acid and significant reduction of the MPT in liver mitochondria incubated with the bile acid. Taken together, these results support an antioxidative and anti-apoptotic role of $\beta C$ under conditions that may exist in the cholestatic liver.

The cytoprotective effects of $\beta C$ reported in this study provide evidence that $\beta \mathrm{C}$ may protect mammalian cells that are subjected to oxidative stress-dependent apoptosis. Although the antioxidative function of $\beta \mathrm{C}$ in vivo is a source of considerable controversy $(38,39)$, there is extensive evidence that $\beta C$ functions as an antioxidant under a variety of in vitro conditions. In the original study by Burton and Ingold (6), $\beta C$ prevented peroxidation of methyl linoleate in a unique manner when compared with previously characterized mechanisms of other antioxidants. The hypothesized mechanism of $\beta \mathrm{C}$ antioxidant protection against lipid oxidation was that of a chainbreaking antioxidant by efficient trapping of peroxyl radicals resulting in generation of lipid hydroperoxides. As hydrophobic bile acids have been shown to increase generation of hydroperoxides $(17,19)$, it is possible that $\beta C$ functioned as an antioxidant in the current study by protecting membrane lipids from propagating oxidative damage through termination of peroxyl radical-mediated reactions. Inhibition of DCFein flu-

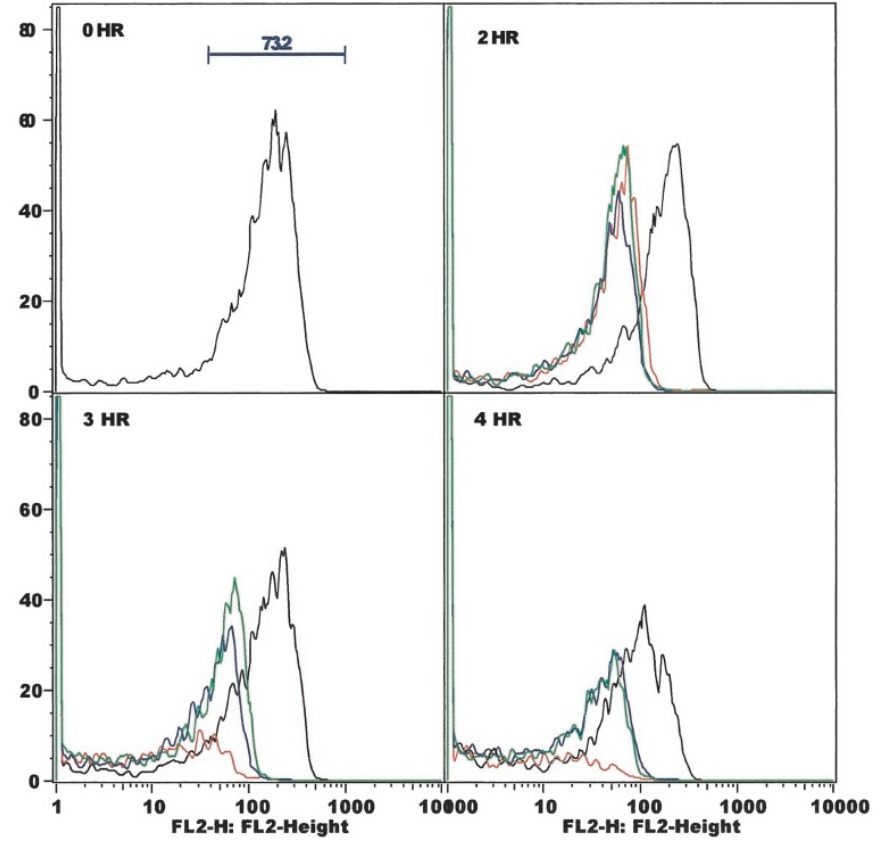

Figure 6. The effect of $\beta C$ on GCDC-induced collapse of mitochondrial $\Delta \psi$ in rat hepatocytes. Isolated rat hepatocytes were exposed to $100 \mu \mathrm{M} \mathrm{GCDC}$ in the absence or presence of $50-100 \mu \mathrm{M} \beta \mathrm{C}$. Hourly aliquots were removed, loaded with JC- 1 and PI for $15 \mathrm{~min}$ at $22^{\circ} \mathrm{C}$, and washed with $\mathrm{KRH}$ buffer before fluorescence determination at $590 \mathrm{~nm}$ for JC-1. JC-1 aggregate fluorescence in live cells (PI-negative), which represents an intact mitochondrial $\Delta \psi$, was significantly reduced by $2 \mathrm{~h}$ of incubation with GCDC (red line) compared with untreated cells (black line). Preincubation of hepatocytes with either $50 \mu \mathrm{M} \beta \mathrm{C}$ (blue line) or $100 \mu \mathrm{M} \beta \mathrm{C}$ (green line) prevented the GCDC-induced reduction in JC-1 aggregate fluorescence, indicating that the bile acid-induced mitochondrial depolarization was inhibited by $\beta C$. $\beta C$ alone failed to affect JC-1 aggregate fluorescence when compared with control cells (data not shown). The horizontal bar indicates the percentage of the population of cells exhibiting the designated fluorescence. Results shown are representative of at least two separate experiments.

orescence, a measurement of intracellular peroxide generation, by $\beta C$ would support this antioxidative mechanism. A second, less likely explanation for the reduction of ROS generation by $\beta C$ was its role as a quencher of electronically excited singlet oxygen $(40,41)$. Although studies have reported generation of singlet oxygen in hepatocytes (42), no evidence exists that this photochemically generated intermediate is produced in bile acid-treated hepatocytes under the conditions used in this study (which did not use photosensitizing agents).

At the higher concentration of $\beta C$ used in this study (100 $\mu \mathrm{M}$ ), we observed a significant inhibition of GCDC-induced generation of ROS, reduction of cellular apoptosis, and reduced cell necrosis. It is interesting that when a lower concentration of the carotenoid was examined $(50 \mu \mathrm{M})$, we observed nearly identical antioxidant and anti-apoptotic protection to that of the higher dose but a lesser degree of protection against cellular necrosis. A similar observation was noted when comparing the effects of a combination of $\beta \mathrm{C}$ and $\alpha$-TH $(100 \mu \mathrm{M}$ each) toward ROS generation (Fig. 1c) and cellular necrosis (Fig. 2c), where the combination failed to decrease ROS generation further yet provided increased protection against necrosis, suggesting that once a maximal level of antioxidant protection is achieved, increased potentiation against cellular 
necrosis continued. Explanations for the increased cytoprotection conferred by $100 \mu \mathrm{M} \beta \mathrm{C}$ include 1) possible nonantioxidant functions for the carotenoid (43), 2) increased concentrations of the carotenoid or a retinoid metabolite (44), and 3) increased intra- or extracellular effects that increase cell stabilization against necrotic cell death. Such findings are not surprising given the myriad of structural and metabolic events implicated in bile acid-induced necrotic cell death, including alterations in $\mathrm{Ca}+2$ homeostasis, ATP depletion, and activation of cellular proteolytic pathways (45). These data suggest that pathways involved in bile acid-induced hepatocyte apoptosis, such as activation of caspases and mitochondrial release of cytochrome c into the cytosol, may be more sensitive to cellular redox status compared with processes that are observed during necrosis.

The current finding of a potent anti-apoptotic effect of $\beta \mathrm{C}$ in a normal cell model is in contrast to studies using tumor cell models. For example, a study with human adenocarcinoma cells found that $\beta \mathrm{C}$ at concentrations up to $100 \mu \mathrm{M}$ exhibited pro-oxidative and pro-apoptotic effects including decreased expression of the anti-apoptotic protein BCL-2 (46). $\beta$ C's differential effects between freshly isolated rat hepatocytes and cultured tumor cells can be explained by a variety of experimental and biologic factors. First, tumor cells have an antioxidant defense mechanism and redox status that contrast with those of normal cells (47). In addition, the uptake and metabolism of $\beta C$ can differ greatly depending on the cell type and mode of $\beta C$ administration $(44,48)$. Other properties of $\beta C$ (or other related carotenoids) that may contribute to its antiapoptotic effects include an antiproliferative effect (49), stimulation of gap junctional communications (50), and regulation of cellular detoxification systems (51). Finally, the metabolism of $\beta C$ to retinoids $(48,50)$ cannot be disregarded as a contributing factor to $\beta C$ 's observed anti-apoptotic effects. However, induction of gene transcription by retinoids through binding of nuclear receptor complexes would not likely occur in the short time frame of the current study using freshly isolated (not cultured) hepatocytes.

The protective role of $\beta \mathrm{C}$ in the current study is supportive of the hypothesis that oxidant stress is a crucial step in the pathogenesis of bile acid-induced toxicity. Many laboratories have linked generation of an oxidant stress to pro-apoptotic events in liver mitochondria and intact hepatocytes $(19,22)$. For example, we have demonstrated that GCDC induced the MPT in liver mitochondria and stimulated the release of cytochrome c from mitochondria into cytosol and loss of mitochondrial $\Delta \psi$ in hepatocytes $(22,25)$, all of which were blocked by antioxidants. These findings, now extended with the current results with $\beta C$, clearly implicate oxidative stress and mitochondrial dysfunction in the pathogenesis of bile acid-induced cytotoxicity. Although the evidence herein supports a role for the antioxidant effect of $\beta \mathrm{C}$ in this cytoprotection, as stated above, one cannot discount the possibility that $\beta \mathrm{C}$ also possesses nonantioxidant functions that are also operative.

In summary, the current study provides additional evidence that oxidative stress and mitochondrial dysfunction play critical roles in bile acid-induced hepatocyte toxicity, an important mediator of hepatocyte injury in the cholestatic liver (52).
Moreover, the results demonstrate for the first time that $\beta \mathrm{C}$ can prevent biochemical and morphologic evidence of cell necrosis and apoptosis in rat hepatocyte suspensions that are exposed to toxic, hydrophobic bile acids. The protection afforded by this nutrient was consistent with its role as an antioxidant of biologic importance. Consideration of using $\beta \mathrm{C}$ in humans, as was recently done in a pilot study with patients with CLD (14), must take into account the possible adverse effects of the compound under certain circumstances. Questions of potential toxicity of $\beta C$ have arisen during intervention studies in which $\beta C$ supplementation in long-term cigarette smokers was associated with increased susceptibility to lung cancer and coronary artery disease $(7,8)$. Lieber's laboratory has also provided evidence in both cells and baboons suggesting that a toxic interaction may arise between $\beta \mathrm{C}$ and ethanol administration, perhaps by a mechanism involving common metabolic detoxification pathways $(53,54)$. Nevertheless, additional studies into the mechanisms and relevance of $\beta \mathrm{C}$ as a potential hepatoprotective agent in childhood cholestasis are warranted.

Acknowledgments. Presented in part at the 52nd Annual Meeting of the American Association for the Study of Liver Diseases, Dallas, TX, November 2001 [Hepatology 2001;34:277A(abstr)].

\section{REFERENCES}

1. Frei B 1994 Natural Antioxidants in Human Health and Disease. Academic Press, San Diego

2. Sies H 1997 Antioxidants in Disease Mechanisms and Therapy, Vol 38, Advances in Pharmacology. Academic Press, San Diego

3. Gopalakrishna R, Gundimeda U 2002 Antioxidant regulation of protein kinase C in cancer prevention. J Nutr 132:3819S-3823S

4. Toivanen JL 1987 Effects of selenium, vitamin E and vitamin C on human prostacyclin and thromboxane synthesis in vitro. Prostaglandins Leukot Med 26:265-280

5. Olson JA 1999 Carotenoids. In: Shils ME, Olson JA, Shike M, Ross AC (eds) Modern Nutrition in Health and Disease, 9th Ed. Williams \& Wilkins, Baltimore, pp 525-542

6. Burton GW, Ingold KU $1984 \beta$-Carotene: an unusual type of lipid antioxidant. Science 224:569-573

7. Alpha-Tocopherol, $\beta$-Carotene Cancer Prevention Study Group 1994 The effect of vitamin $\mathrm{E}$ and beta carotene on the incidence of lung cancer and other cancers in male smokers. N Engl J Med 330:1029-1035

8. Kritharides L, Stocker R 2002 The use of antioxidant supplements in coronary heart disease. Atherosclerosis 164:211-219

9. Dietary reference intakes for vitamin C, vitamin E, selenium, and carotenoids A Report of the Panel on Dietary Antioxidants and Related Compounds, Subcommittees on Upper Reference Levels of Nutrients and of Interpretation and Use of Dietary Reference Intakes 2000 Food and Nutrition Board, Institute of Medicine, National Academy Press Washington, DC

10. Leo MA, Ahmed S, Aleynik SI, Siegel JH, Kasmin F, Lieber CS 1995 Carotenoids and tocopherols in various hepatobiliary conditions. J Hepatol 23:550-556

11. Phillips JR, Angulo P, Petterson T, Lindor KD 2001 Fat-soluble vitamin levels in patients with primary biliary cirrhosis. Am J Gastroenterol 96:2745-2750

12. Floreani A, Baragiotta A, Martines D, Naccarato R, D'odorico A 2000 Plasma antioxidant levels in chronic cholestatic liver diseases. Aliment Pharmacol Ther $14: 353-358$

13. Sokol RJ, Devereaux MW, Gumpricht E 2001 Inhibition of bile acid-induced mitochondrial permeability transition by dietary antioxidants. Hepatology 34:277A(abstr)

14. Watson JP, Jones DE, James OF, Cann PA, Branble MG 1999 Case report: oral antioxidant therapy for the treatment of primary biliary cirrhosis: a pilot study. J Gastroenterol Hepatol 14:1034-1040

15. Starzl TE, Demetros AJ, Van Thiel D 1989 Liver transplantation (1). N Engl J Med 321:1014-1022

16. Bove KE, Daugherty CC, Tyson W, Mireau G, Heubi JE, Balistreri WF, Setchell KD 2000 Bile acid synthetic defects and liver disease. Pediatr Dev Pathol 3:1-16

17. Sokol RJ, Winklhofer-Roob BM, Devereaux MW, McKim JM 1995 Generation of hydroperoxides in isolated rat hepatocytes and hepatic mitochondria exposed to hydrophobic bile acids. Gastroenterology 109:1249-1256

18. Sokol RJ, McKim JM, Goff MC, Ruyle SZ, Devereaux MW, Han D, Packer L, Everson G 1998 Vitamin E reduces oxidant injury to mitochondria and the hepatotoxicity of taurochenodeoxycholic acid in the rat. Gastroenterology 114:164-174 
19. Rodrigues CM, Fan G, Ma X, Kren BT, Steer CJ 1998 A novel role for ursodeoxycholic acid in inhibiting apoptosis by modulating mitochondrial membrane perturbation. J Clin Invest 101:2790-2799

20. Patel T, Bronk SF, Gores GJ 1994 Increases of intracellular magnesium promote glycodeoxycholate-induced apoptosis in rat hepatocytes. J Clin Invest 94:2183-2192

21. Gumpricht E, Devereaux MW, Dahl RH, Sokol RJ 2000 Glutathione status of isolated rat hepatocytes affects bile acid-induced cellular necrosis but not apoptosis. Toxicol Appl Pharmacol 164:102-111

22. Sokol RJ, Straka MS, Dahl R, Devereaux MW, Yerushalmi B, Gumpricht E, Elkins N, Everson G 2001 Role of oxidant stress in the permeability transition induced in rat hepatic mitochondria by hydrophobic bile acids. Pediatr Res 49:519-531

23. Botla R, Spivey JR, Aguilar H, Bronk SF, Gores GJ 1995 Ursodeoxycholate (UDCA) inhibits the mitochondrial membrane permeability transition induced by glycochenodeoxycholate: a mechanism of UDCA cytoprotection. J Pharmacol Exp Ther 272:930-938

24. Gores GJ, Miyoshi H, Botla R, Aguilar HI, Bronk SF 1998 Induction of the mitochondrial permeability transition as a mechanism of liver injury during cholestasis: a potential role for mitochondrial proteases. Biochim Biophys Acta 1366:167-175

25. Yerushalmi B, Dahl R, Devereaux MW, Gumpricht E, Sokol RJ 2001 Bile acidinduced rat hepatocyte apoptosis is inhibited by antioxidants and blockers of the mitochondrial permeability transition. Hepatology 33:616-626

26. Crompton M 1999 The mitochondrial permeability transition pore and its role in cell death. Biochem J 341:233-249

27. Pastorino JG, Snyder JW, Serroni A, Hoek JB, Farber JL 1993 Cyclosporin and carnitine prevent the anoxic death of cultured hepatocytes by inhibiting the mitochondrial permeability transition. J Biol Chem 268:13791-13798

28. Ott M, Robertson JD, Gogvadze V, Zhivotovsky B, Orrenius S 2002 Cytochrome c release from mitochondria proceeds by a two-step process. Proc Natl Acad Sci U S A 99:1259-1263

29. Kowaltowski AJ, Castilho RF, Vercesi AE 2001 Mitochondrial permeability transition and oxidative stress. FEBS Lett 495:12-15

30. Leist M, Volbracht C, Fava E, Nicotera P 1998 1-Methyl-4-phenylpyridinium induces autocrine excitotoxicity, protease activation, and neuronal apoptosis. Mol Pharmacol 54:789-801

31. Qiao L, Studer E, Leach K, McKinstry R, Gupta S, Decker R, Kukreja R, Valerie K, Nagarkatt P, El Deiry W, Molkentin J, Schmidt-Ullrich R, Fisher PB, Grant S, Hylemon PB, Dent P 2001 Deoxycholic acid (DCA) causes ligand-independent activation of epidermal growth factor receptor (EGFR) and FAS receptor in primary hepatocytes: inhibition of EGFR/mitogen-activated protein kinase-signaling module enhances DCA-induced apoptosis. Mol Biol Cell 12:2629-2645

32. Lowry OH, Rosebrough NJ, Farr AL, Randall RJ 1951 Protein measurement with the Folin-phenol reagent. J Biol Chem 193:265-275

33. Bradford MM 1976 A rapid and sensitive method for the quantitation of microgram quantities of protein utilizing the principle of protein-dye binding. Anal Biochem $72: 248-254$

34. Gumpricht E, Dahl RH, Yerushalmi B, Devereaux MW, Sokol RJ 2002 Nitric oxide ameliorates hydrophobic bile acid-induced apoptosis in isolated rat hepatocytes by non-mitochondrial pathways. J Biol Chem 277:25823-25830
35. Tanumihardjo SA, Furr HC, Amedee-Manesme O, Olson JA 1990 Retinyl ester (vitamin A ester) and carotenoid composition in human liver. Int J Vitam Nutr Res 60:307-313

36. Leo MA, Rosman AS, Lieber CS 1993 Differential depletion of carotenoids and tocopherol in liver disease. Hepatology 17:977-986

37. Berry MN, Edwards AM, Barritt GJ 1991 Biochemical properties. In: Burdon RH, van Knippenberg (eds) Isolated Hepatocytes: Preparation, Properties, and Applications. Elsevier Science Publishing Co., New York, pp 121-178

38. Crabtree DV, Adler AD 1997 Is beta-carotene an antioxidant? Med Hypotheses 48:183-187

39. Rice-Evans CA, Sampson J, Bramley PM, Holloway DE 1997 Why do we expect carotenoids to be antioxidants in vivo? Free Radic Res 26:381-398

40. Foote CS, Denny RW 1968 Chemistry of singlet oxygen VII quenching by $\beta$-carotene. J Am Chem Soc 90:6233-6235

41. Liebler DC 1993 Antioxidant reactions of carotenoids. Ann N Y Acad Sci 691:20-31

42. Cadenas E, Wefers H, Sies H 1981 Low-level chemiluminescence of isolated hepatocytes. Eur J Biochem 119:531-536

43. Stahl W, Ale-Agha N, Polidori MC 2002 Non-antioxidant properties of carotenoids. Biol Chem 383:553-558

44. Williams AW, Boileau TW, Clinton SK, Erdman JW 2000 ßeta-carotene stability and uptake by prostate cancer cells are dependent on delivery vehicle. Nutr Cancer 36:185-190

45. Spivey JR, Bronk SF, Gores GJ 1993 Glycochenodeoxycholate-induced lethal hepatocellular injury in rat hepatocytes. Role of ATP depletion and cytosolic free calcium. J Clin Invest 92:17-24

46. Palozza P, Calviello G, Serini S, Maggiano N, Lanza P, Ranelletti FO, Bartoli GM $2001 \beta$-Carotene at high concentrations induces apoptosis by enhancing oxyradical production in human adenocarcinoma cells. Free Radic Biol Med 30:1000-1007

47. Cheeseman KH, Emery S, Maddix SP, Slater TF, Burton GW, Ingold KU 1988 Studies on lipid peroxidation in normal and tumour tissues. The Yoshida rat liver tumour. Biochem J 250:247-252

48. Wei RR, Wamer WG, Lambert LA, Kornhauser A $1998 \beta$-Carotene uptake and effects on intracellular levels of retinol in vitro. Nutr Cancer 30:53-58

49. Carpenter K, Hardwick SJ, Albarani V, Mitchinson MJ 1999 Carotenoids inhibit DNA synthesis in human aortic smooth muscle cells. FEBS Lett 447:17-20

50. Stahl W, Sies H 2001 Effects of carotenoids and retinoids on gap junctional communication. Biofactors 15:95-98

51. Kessova IG, Leo MA, Lieber CS 2001 Effect of beta-carotene on hepatic cytochrome P-450 in ethanol-fed rats. Alcohol Clin Exp Res 25:1368-1372

52. Greim H, Czygan P, Schaffner F, Popper H 1973 Determination of bile acids in needle biopsies of human liver. Biochem Med 8:280-286

53. Ni R, Leo AM, Zhao J, Lieber CS 2001 Toxicity of beta-carotene and its exacerbation by acetaldehyde in HepG2 cells. Alcohol Alcohol 36:281-285

54. Leo MA, Kim CI, Lowe N, Lieber CS 1992 Interaction of ethanol with beta-carotene: delayed blood clearance and enhanced hepatotoxicity. Hepatology 15:883-891 